acid and proceed directly with the titration as soon as solution was complete. But iron is almost always present in such alloys to a considerable amount, and hence the necessity for a more roundabout method. Dissolve one gram in either nitric or hydrochloric acid. Add a few crystals of citric acid, make ammoniacal, and heat to boiling. Remove from the source of heat and add a little colorless ammonium sulphide. Allow to settle and then filter, being careful to wash out the last traces of citric acid with a wash water containing a little anmonium sulphide. The precipitate will consist of sulphide of zinc, iron and copper metals. Treat it exactly as described for brasses under similar conditions. If desired, the metal may be dissolved in hydrochloric acid and the zinc precipitated as sulphide from a slightly acid solution just as when it is required to separate it from nickel.

In general, any one working intelligently, realizing the final conditions and knowing something of the material in hand, will find no difficulty in following out the plan of this method.

LABoratory of Booth, Garrett \& Blair, Philadelphia.

\title{
THE DETERMINATION OF BENZENE IN ILLUMINATING GAS.
}

By L. M. Dennis and Ellen S. Mocarthy.

Received November 25, 1907.

\section{The Absorption of Benzene by Ammoniacal Nickel Nitrate.}

In I903 Dennis and O'Neill described ${ }^{1}$ an absorption method for the determination of benzene in illuminating gas. The absorbent there recommended was an ammoniacal solution of nickel nitrate, the use of such a solution for the determination of benzene having been suggested by the statement of Hofmann and Küspert ${ }^{2}$ that when illuminating gas acts upon a mixture of nickel hydroxide and ammonia, there is formed a compound of nickel cyanide with ammonia and benzene, $\mathrm{Ni}(\mathrm{CN})_{2}$. $\mathrm{NH}_{3} \cdot \mathrm{C}_{8} \mathrm{H}_{6}$.

In practice, this method for the determination of benzene in some localities, has given most excellent results, while in other quarters it has been far from satisfactory. Morton recently demonstrated ${ }^{3}$ that when mixtures of benzene and air are analyzed with the use of the reagent, the results are scarcely better than might be obtained with water alone, and that, moreover, the efficiency of the absorbent steadily decreases as the amount of benzene that it has taken up increases. These statements of Morton have been substantiated in this laboratory and the

${ }^{1}$ This Journal, 25, 503.

2 Z. anorg. Chem., I5, 204 (1897.)

${ }^{3}$ This Journal, 28, 1728 (1906). 
only explanation of the excellence of the results in the analyses of mixtures of air and benzene as published by Dennis and O'Neill would seem to lie in the fact that but few absorptions of benzene were made and that, consequently, the reagent had not taken up sufficient benzene to render the loss in its absorbing power noticeable.

Confronting the facts adduced by Morton, however, were arrayed statements from several Lniversity and technical laboratories testifying to the satisfactory character of the method and the uniformity of results obtained by it in analyses of illuminating gas. In seeking for explanation of these variations in the reports of different chemists it occurred to the authors of the present paper that those samples of illuminating gas on which the method gave good results might have contained cyanogen compounds necessary to the formation of the compound that Hofmann and Küspert described, while the poor results on other samples of illuminating gas might be caused by the absence of cyanogen compounds from the gas. To test the validity of this assumption, the ammoniacal nickel nitrate solution recommended by Dennis and O'Neill was used in a series of analyses of a gas mixture containing benzene, hydrocyanic acid and air.

The hydrocyanic acid gas for these analyses was prepared by filling a Hempel nitrometer with mercury, then introducing from five to ten cubic centineters of a concentrated solution of potassium cyanide and adding gradually through the side arm about the same volume of hydrochloric acid (one part of acid to one part of water). The gas set free by this reaction was completely absorbable by caustic potash. It probably contained small amounts of cyanogen and carbon dioxide but it will be referred to below as "hydrocyanic acid." A mixture of this gas with benzene and air was obtained by measuring off a volume of air, then passing this into a Hempel simple gas pipette containing liquid benzene, drawing the gas back into the burette and noting the increase in volume, and finally drawing into the burette the hydrocyanic acid gas that had been evolved in the nitrometer, and again measuring the volune. The measurements were made in a jacketed Hempel gas burette with nercury as the confining liquid. Several mixtures prepared in this manner were analyzed by the Dennis and O'Neill method. The same sample of ammoniacal nickel nitrate was enployed for all of the absorptions listed in Tables I, II and III.

Table I gives the results obtained with the mixture of air, benzene and hydrocyanic acid. The completeness of the absorption may be seen by comparing the volume of air taken with the volume of gas remaining after absorption. It will be noted that the agreement is practically exact in every case except the $4^{\text {th. }}$ 
TABLE I.

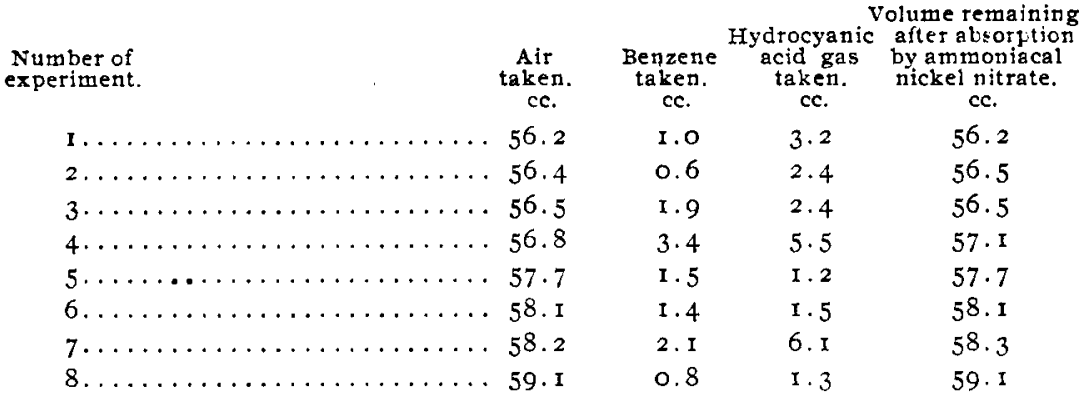

While the above table demonstrates that, in the presence of cyanogen compounds, ammoniacal nickel nitrate quantitatively absorbs benzene vapor, the accurate results obtained by sone analysts with the reagent could even yet not be explained, if these cyanogen compounds in a gas mixture are completely removed by potassium hydroxide, the reagent that precedes the ammoniacal nickel nitrate in the analysis of illuminating gas. To ascertain whether any of the cyanogen compounds are left in the gas mixture after it has been passed into the potassium hydroxide pipette, the analyses given in Table II were made. In each analysis the gas mixture was allowed to remain in the potassium hydroxide pipette for such a length of time as had been found to suffice for the absorption of all of the hydrocyanic acid when that was mixed with air alone. The results show that when hydrocyanic acid, benzene and air are present together, potassium hydroxide does not remove all of the hydrocyanic acid, the benzene appearing to exert a deterrent effect upon the absorption. It will be noted that the ammoniacal nickel nitrate quantitatively removed the benzene and the residual hydrocyanic acid in nearly every case.

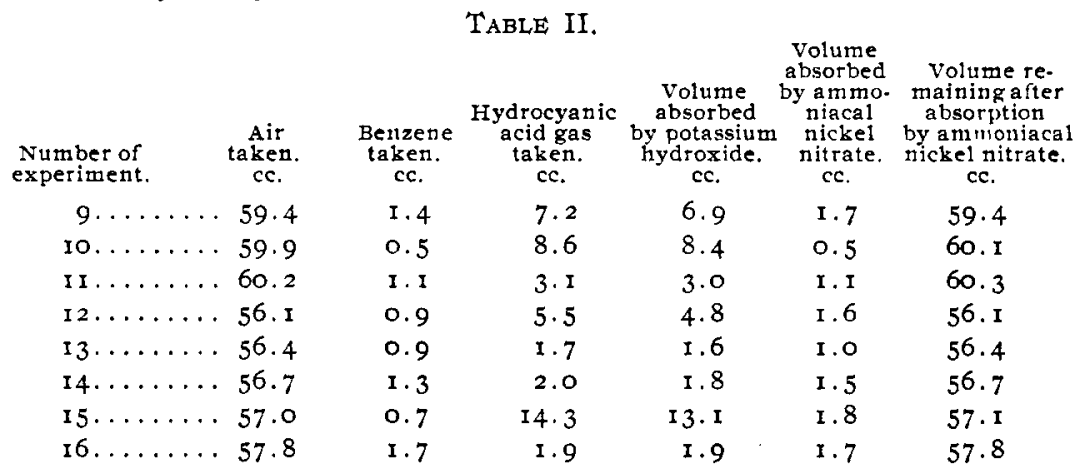

If, from the results in the above table, we are justified in assuming that after treatment with caustic potash some cyanogen compounds still remain in illuminating gas, it at once becomes evident why the 
Dennis and O'Neill method gave satisfactory results with such samples of illuminating gas as contained cyanogen compounds.

After the first three determinations in lable II had been made, it was thought possible that the anmoniacal nickel nitrate had then taken up sufficient hydrocyanic acid to enable it to absorb benzene vapor without the addition of further hydrocyanic acid gas to the mixture. This assumption seems also to be borne out by the fact that in Deterninations II and $I_{3}$ the absorption of benzene was complete even when only I/ Io of a cubic centimeter of "hydrocyanic acid" gas was present with the benzene vapor. The results of these analyses are given in Table III.

TABLE III.

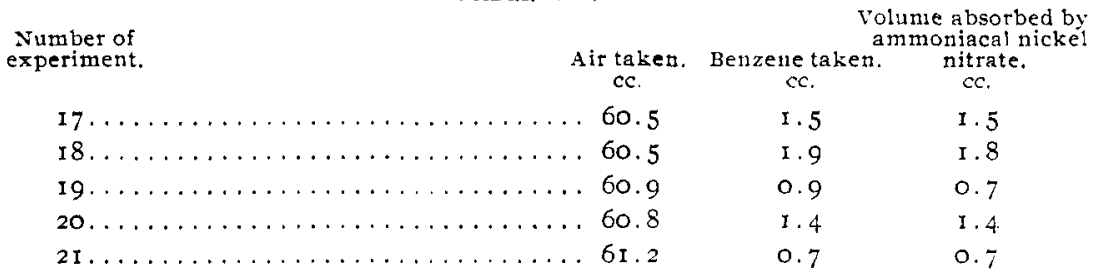

The results, Nos. 12 to 21 inclusive, demonstrate that after the an1moniacal nickel nitrate has taken up some cyanogen it is able quantitatively to absorb fairly large amounts of benzene vapor, and that if cyanogen compounds are present in illuminating gas, the benzene content may accurately be determined by the nethod of Dennis and O'Neill. If, however, the reagent contains no cyanogen compounds and if nonc are present in the gas that is being analyzed the method will not give accurate results.

\section{The Absorption of Benzene by Ammoniacal Nickel Cyanide.}

The foregoing experiments having demonstrated that a solution of ammoniacal nickel nitrate cannot be relied upon for the absorption of benzene from all samples of illuminating gas, the necessity arose for such modification of the method as would render it uniformly accurate.

It is apparent that to insure complete absorption of the benzene from all gas mixtures through the formation of the ammonia benzene nickel cyanide, cyanogen must be present in every case. This led to the usc of an ammoniacal solution of nickel cyanide ${ }^{1}$ as an absorbent in place of the ammoniacal solution of nickel nitrate.

Preparation of the Ammoniacal Solution of Nickel Cyanide.-To 50 grams of nickel sulphate $\left(\mathrm{NiSO}_{4} \cdot 7 \mathrm{H}_{2} \mathrm{O}\right)$, dissolved in $75 \mathrm{cc}$. of water, are added 25 grams of potassium cyanide dissolved in $40 \mathrm{cc}$. of water. After the addition of $125 \mathrm{cc}$. of ammonimm hydroxide (Sp. Gr. 0.9I) the mixture is shaken until the nickel cyanide has completely dissolved and is then

1 See also Hofmann and Arnoldi, Ber, 39, 339 (r9o6). 
allowed to stand at a temperature of $0^{\circ}$ for twenty minutes. The clear liquid is decanted from the crystals of potassium sulphate that have been precipitated, and is treated with a solution prepared by dissolving i 8 grams of crystallized citric acid in Io cc. of water. After the mixture has stood again at $0^{\circ}$ for ten minutes, the greenish blue supernatant solution is decanted and is introduced into a gas pipette. Two drops of liquid benzene are now added to the reagent through the large tube of the pipette and the pipette is shaken until the benzene has combined with the reagent. This is effected in two or three minutes. This addition of benzene to the reagent is made because it was found that at times a freshly prepared solution of the ammoniacal nickel cyanide did not quantitatively remove benzene vapor until it had been used for four or five determinations and had absorbed some of the substance. Hofmann and Arnoldi used acetic acid in the preparation of the absorbent. This we have replaced by citric acid because of the appreciable vapor tension of acetic acid at ordinary temperatures.

Apparatus Employed.-The reagent was placed in a Hempel gas pipette of the form used for the absorption of heavy hydrocarbons by means of fuming sulphuric acid, the upper bulb that is filled with broken glass being, however, $4.6 \mathrm{~cm}$. in diameter which is somewhat larger than in the usual Hempel pipette. The measurements of the gas volumes were made in a Hempel gas burette provided with a water jacket and if changes of temperatures occurred, corrections were made for them. Numerous experiments showed that satisfactory results nay be obtained with either water or mercury as the confining liquid in the burette.

Analytical Procedure.-After the sample of gas has been measured in the burette, the burette is connected by means of the usual capillary tube with a pipette containing the ammoniacal nickel cyanide solution, and the gas mixture is repeatedly passed over into the pipette and drawn back into the burette for a period of about two minutes. The pipette is then disconnected and the gas is passed into a "fuming sulphuric acid" Hempel gas pipette containing a five per cent. solution of sulphuric acid, this being done to remove the ammonia that enters the gas mixture from the reagent. The ammonia is not easily absorbed by the dilute sulphuric acid and the gas mixture must, consequently, be passed into and withdrawn from the pipette repeatedly for about two minutes to effect its complete removal.

Experimental Results.-The experiments that were made to ascertain the applicability of the reagent to the absorption of benzene and the accuracy of the method may be classified under the following heads:

(I) Determination of Benzene in Known Mixtures of Benzene and Air; 
(2) Study of the Behavior of an Ammoniacal Solution of Nickel Cyanide toward Known Mixtures of Ethylene and Air;

(3) The Determination of Benzene in Coal Gas;

(4) The Determination of the "Analytical Absorbing Power" of the Ammoniacal Solution of Nickel Cranide:

(5) The Determination of Benzene in Coal Gas that Had Been Freed from the Benzene that it Originally Contained and Had Been Mixed with Known Volumes of Benzene Vapor; and

(6) The Determination of the Vapor Tension (with Reference to Benzene) of the Partially Exhausted Reagent.

(1) The Determination of Benzene in Known Mixtures of Benzene and Air.-Air was drawn into the gas burette and measured. It was next passed into a gas pipette containing mercury and a few cubic centimeters of liquid benzene, and was then drawn back into the burette and the increase in volume was noted. The percentage of benzene was then deternined by absorption with the ammoniacal solution of nickel cyanide with the subsequent removal of the ammonia by dilute sulphuric acid in the manner described above. A large number of these analyses was made. The few results in Table IV illustrate the average efficiency of the method.

TABLE IV.

\begin{tabular}{|c|c|c|c|c|c|}
\hline $\begin{array}{l}\text { Number of } \\
\text { experiment. }\end{array}$ & $\begin{array}{c}\text { Benzene } \\
\text { taken. } \\
\text { Per cent. }\end{array}$ & $\begin{array}{l}\text { Benzene } \\
\text { found. } \\
\text { Per cent. }\end{array}$ & $\begin{array}{l}\text { Number of } \\
\text { experiment. }\end{array}$ & $\begin{array}{l}\text { Benzene } \\
\text { taken. } \\
\text { Percent. }\end{array}$ & $\begin{array}{l}\text { Benzen } \\
\text { found. } \\
\text { Percen }\end{array}$ \\
\hline $22 \ldots$ & $\ldots 2.3$ & 2.3 & $28 \ldots$ & $\ldots .6$ & 1.6 \\
\hline $23 \ldots$ & . 2.6 & 2.6 & $29 \ldots$. & . I I. 8 & I. 8 \\
\hline $24 \ldots$ & I. 2 & 1.3 & $30 \ldots$ & I. 8 & I. 7 \\
\hline $25 \ldots$ & . 4.9 & $4 \cdot 9$ & $31 \ldots$ & $5 \cdot 2$ & $5 . \mathrm{I}$ \\
\hline $26 \ldots$ & . $5 . I$ & $5 \cdot 1$ & $32 \ldots$ & 2.7 & 2.7 \\
\hline $27 \ldots$ & 2.7 & 2.7 & & & \\
\hline
\end{tabular}

(2) A Study of the Behavior of an Ammoniacal Solution of Nickel Cyanide towards Known Mixtures of Ethylene and Air.-Ethylene was prepared by reducing an alcoholic solution of pure ethylene bromide with a zinc-copper couple. The ethylene employed in the first experiments was made in a flask and the resulting gas was found to contain about 90 per cent. of ethylene. In later experiments the preparation was carried on in a Hempel nitrometer, and the resulting ethylene was then found to be completely absorbable by 20 per cent. fuming sulphuric acid. Mixtures of ethylene and air were prepared and passed over into the anmoniacal nickel cyanide. In no case was any absorption of ethylene noted after the reagent had been shaken once with the gas mixture and thus saturated with it. The data of two experiments are given as illustrative of the results here obtained: Per cent. of ethylene taken 4.3 , found 0.0 ; again, ethylene taken 10.4 , found 0.0 . 
(3) The Determination of Benzene in Coal Gas.-A large number of determinations of the benzene naturally occurring in coal gas was made by the above method and the results are given in Table V. It is perhaps unnecessary to state that here, as in all other absorption methods in gas analysis, freshly prepared reagents should first be shaken with the sample of the gas to be analyzed in order to saturate the reagent with the slightly soluble constituents of the gas mixture. Moreover, the same sample of reagent should not be used for the analysis of gas mixtures of markedly different compositions.

\section{TABLE V.}

\begin{tabular}{|c|c|c|c|c|}
\hline $\begin{array}{l}\text { Number of } \\
\text { experiments }\end{array}$ & Date. & $\begin{array}{r}\text { Time of } \\
\text { with re } \\
\text { Min }\end{array}$ & $\begin{array}{l}f \text { contact } \\
\text { eagent. } \\
\text { nutes. }\end{array}$ & $\begin{array}{l}\text { Benzene } \\
\text { found } \\
\text { Per cent. }\end{array}$ \\
\hline 33 & Jan. & $7 \ldots \ldots \ldots \ldots \ldots \ldots \ldots \ldots \ldots \ldots \ldots$ & 4 & 0.8 \\
\hline 34 & Jan. & 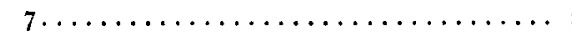 & 2 & 0.8 \\
\hline \multirow[t]{2}{*}{35} & Jan. & 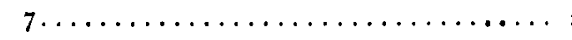 & 2 & 0.8 \\
\hline & & & 4 more & 0.8 \\
\hline 36 & Feb. & 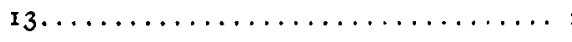 & 2 & 0.7 \\
\hline 37 & Feb. & 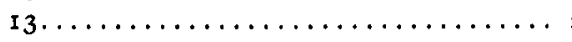 & 2 & 0.7 \\
\hline 38 & Feb. & 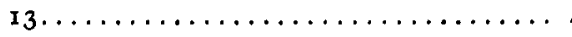 & 4 & 0.7 \\
\hline 39 & Feb. & 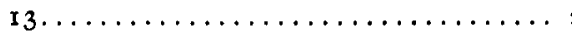 & 2 & 0.7 \\
\hline 40 & Feb. & 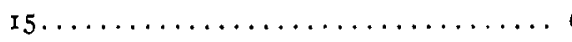 & 6 & 0.6 \\
\hline $4 \mathrm{I}$ & Feb. & 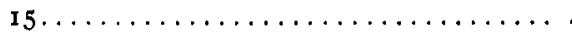 & 4 & 0.6 \\
\hline 42 & Feb. & 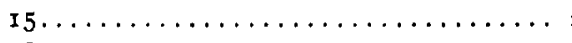 & 2 & 0.6 \\
\hline 43 & Feb. & 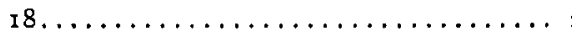 & 2 & 0.8 \\
\hline \multirow{2}{*}{44} & Feb. & 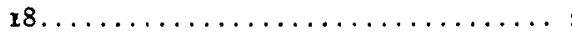 & 2 & 0.8 \\
\hline & & & 2 more & 0.8 \\
\hline 45 & Feb. & $18 \ldots \ldots \ldots \ldots \ldots \ldots \ldots$ & 6 & 0.8 \\
\hline 46 & Feb. & $\mathbf{\imath} 9 \ldots \ldots \ldots \ldots \ldots \ldots \ldots \ldots \ldots \ldots \ldots \ldots \ldots \ldots \ldots$ & 2 & 0.5 \\
\hline \multirow[t]{2}{*}{47} & Feb. & 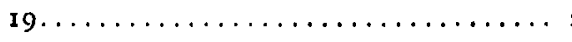 & 2 & 0.5 \\
\hline & & & 2 more & 0.5 \\
\hline 48 & June & 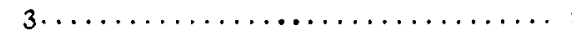 & 2 & I. 2 \\
\hline 49 & June & 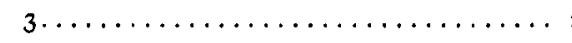 & 2 & I. 2 \\
\hline 50 & June & 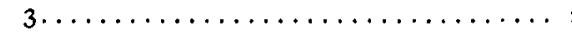 & 2 & $I \cdot 3$ \\
\hline 5 I & June & 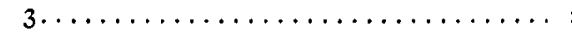 & 2 & 1.2 \\
\hline 52 & June & 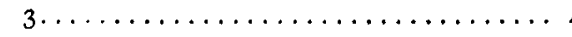 & 4 & 1.2 \\
\hline 53 & June & 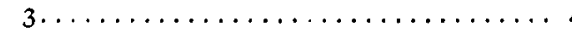 & 4 & I. 2 \\
\hline \multirow[t]{3}{*}{54} & June & 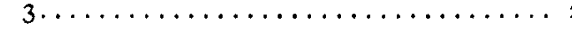 & 2 & I. 2 \\
\hline & & & 2 more & I. 2 \\
\hline & & & 2 more & 1.2 \\
\hline
\end{tabular}

The results tabulated above demonstrate that an ammoniacal solution of nickel cyanide completely removes the benzene from coal gas in two minutes. It should be understood that the gas mixture is repeatedly passed into and drawn out of the gas pipette during this time.

(4) The Determination of the "Analytical Absorbing Power" of the Ammoniacal Solution of Nickel Cyanide.-The term "analytical absorbing power" was introduced by Hempel and means one-fourth of the total volume of the gas that one cubic centimeter of the reagent is able 
io absorb. ${ }^{1}$ Theoretically, one cubic centimeter of the ammoniacal solution of nickel cyanide will absorb about $20 \mathrm{cc}$. of benzene vapor measured under ordinary conditions of temperature and pressure. This corresponds to an "analytical absorbing power" of $5 \mathrm{cc}$ of benzene vapor and inasmuch as the gas pipette holds $200 \mathrm{cc}$. of the reagent, this volume should suffice for the absorption of $1000 \mathrm{cc}$ of benzene vapor. The compound that is formed, $\mathrm{Ni}(\mathrm{CN})_{2} \cdot \mathrm{NH}_{3} \cdot \mathrm{C}_{6} \mathrm{H}_{6}$, exhibits, according to the experiments of Hofmann, no measurable vapor tension.

To ascertain whether this theoretical "analytical absorbing power" was in accord with actual restults, the reagent that had been used in Experiments 48 to 53 inclusive, was shaken with 2 ce. of liquid benzene (equivalent to about $500 \mathrm{cc}$ of benzene vapor) until this was completely absorbed. This reagent was then cunployed in Lxperiment 54 and in Fixperiments 68 to 72 inclusive. The completeness of the absorption obtained in each ease shows conclusively that the linit of the absorbing power of the reagent had not yet been reached ('ven when one filling of the pipette had taken up orer $500 \mathrm{cc}$. of the benzene vapor. Further examination of the absorbing power demonstrated that even after a pipetteful of the reagent had absorled $800 \mathrm{cc}$. of the benzene vapor quantitative results could still be obtained. Since, however, the compound of benzene with the reagent separates as a precipitate, it is advisable, in order to avoid the clogging of the pipette, to filter the reagent after it has taken up fairly large amounts (from 200 to $400 \mathrm{cc}$.) of benzene vapor.

(5) The Determination of Benzene in Known Mixtures of Coal Gas and Benzene.-These deteminations were carried out to ascertain whether benzene can be deternined accuratcly in the presence of the other gases that are ustally found in coal gas. The sanple of coal gas was first freed from benzene by treatment with the ammoniacal nickel cyanide and then known amounts of benzene were added to it in the manner above described.

In Experiments 64 to 67 inclusive, one sample of coal gas was employed and to this successive portions of benzene vapor were added, and were then removed by absorption with the reagent. The fact that the volume of the gas residue remained constant throughout these analyses demonstrates that the constituents of ordinary coal gas other than benzenc (with the exception of those gases absorbed by a concentrated solution of potassium hydroxide) are not absorbed by the reagent. This conclusion is corroborated by the fact that in Experiments 57,58 , and $6 \mathrm{~s}$, a prolongation of the contact between the gas and reagent did not cause further appreciable diminution in the volume of the gas residue.

1 See Hempel, Methods of Gas Analysis, Translated from 3rd German Edition by Dennis, page 145 . 


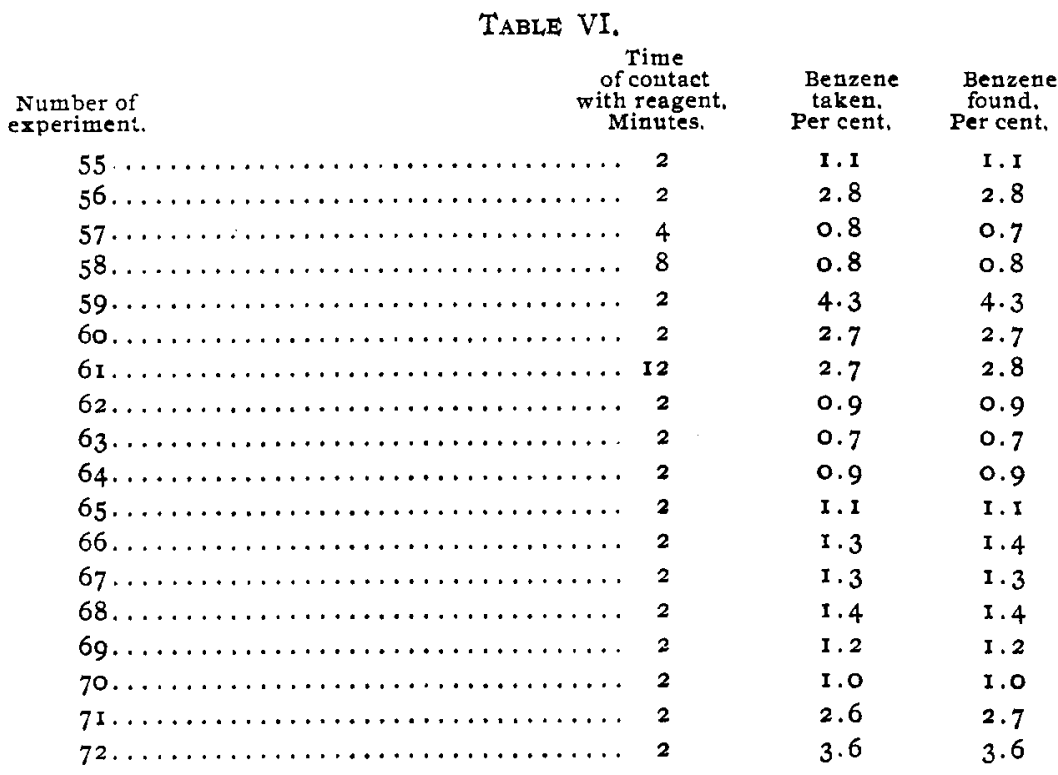

(6) The Determination of the Vapor Tension (with Reference to Benzene) of the Partially Exhausted Reagent.-Although Hofmann states that the ammonia benzene nickel cyanide exhibits no appreciable vapor tension, it was still deemed desirable to ascertain whether the reagent, after somewhat extended use, would show a measurable benzene vapor tension. To this end a measured sample of air was brought into contact with a pipetteful of the reagent that had previously absorbed about $800 \mathrm{cc}$. of benzene vapor. The sample of air was then drawn back into the burette, was passed into a pipette containing dilute sulphuric acid, and was then drawn back into the burette and measured. The results were as follows:

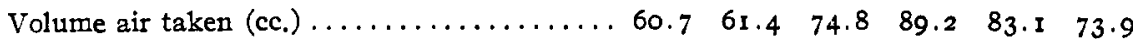
$\begin{array}{lllllllll}\text { Volume after contact with reagent }(c c .) \ldots \ldots & 60.7 & 61.3 & 74.8 & 89.3 & 83.1 & 73.9\end{array}$

From these experiments it appears that the benzene vapor tension of the partially exhausted reagent is so slight as to be negligible.

Dennis and $O^{\prime}$ Neill $^{1}$ determined experimentally that benzene is not taken up by the concentrated solution of potassium hydroxide that is employed in the Hempel method for the determination of carbon dioxide, and that consequently absorption of carbon dioxide may properly precede the determination of benzene. This point has been examined further by the authors of the present paper who also have found that potassium hydroxide solution does not absorb benzene from mixtures of benzene vapor and air. The order of procedure then in the analysis

${ }^{1}$ Loc. cit., p. 507 
of coal gas should be that recommended by Dennis and 0 'Neill, ${ }^{1}$ the absorption of benzene being effected by the ammoniacal solution of nickel cyanide in place of the solution of ammoniacal nickel nitrate which they there suggested.

\section{The Morton Method for the Determination of Benzene in Illuminat- ing Gas.}

D. A. Morton has recently described ${ }^{2}$ a simple method for the determination of benzene by absorption with concentrated sulphuric acid (Sp. Gr. 1.84) and before leaving this work it was thought adrisable to examine Morton's method with a riew to ascertaining the accuracy of the results that can be obtained through its use. It is self-evident that for the determination of benzene in coal gas, there must be employed an absorbent that does not remove ethylene. Norton states that the effect due to the absorption of ethylene by concentrated sulphuric acid is insignificant. 'This statenent is somewhat surprising, for inasmuch as both benzene and ethylene are quantitatively absorbed by fuming sulphuric acid it would seen reasonable to suppose that concentrated sulphuric acid would also take up ethylene, and that, although it might absorb this gas in smaller amounts than did the funing sulphuric acid. the percentages of ethylene removed by it would yet be appreciable. Further, it was deemed possible that the apparently correct results in the separation of benzene and ethylene obtained by Morton might be ascribed to an accidental balancing of errors in the removal of the two gases in question. In looking up the literature of the subject it was found that Frankland and Thorne," in working upon "The Luminosity of Benzol" found "that ordinary sulphuric acid absorbs benzol vapor rather rapidly, and may be used for its eudiometric determination." They were, however, separating benzene from hydrogen, carbon monoxide, and methane, and no ethylene was present in the gas mixture that was employed. Butlerow and Gorjainow ${ }^{4}$ found that concentrated sulphuric acid will completely absorb ethylene at a temperature of from $160^{\circ}$ to $170^{\circ}$. Berthelot ${ }^{5}$ states that when ethylene is shaken witl concentrated sulphuric acid, 100 grams of the acid absorb 6.7 liters (120 volumes) of ethylene, and further that the ethylene that escapes absorption upon passage through a Liebig bulb containing fuming sulphuric acid is afterward absorbed by shaking it with ordinary sulphuric acid. In a paper by Iaraday ${ }^{8}$ it is stated that when ethylene was al-

\footnotetext{
${ }^{1}$ Loc. cit, p. 511.

2 This Journal, 28, 1732 (1906).

${ }^{3} \mathrm{~J}$. Chem. Soc., 33, 89 (1878).

${ }^{4}$ Ber., 6, 196 (1873).

${ }^{5}$ Ann. chim. phys. [3], 43, 385 (1855).

${ }^{6}$ Phil. Trans., r825, p. 448.
} 
lowed to stand for eighteen days in contact with concentrated sulphuric acid one volume of the acid absorbed 84.7 volumes of the ethylene.

\section{Experimental.}

The Absorption of Ethylene by Sulphuric Acid [(Sp. Gr. 1.84).Ethylene was prepared in the manner above described. A mixture of air and ethylene containing 22.5 per cent. of ethylene was made and was shaken for one minute with about $\mathrm{I}_{5} \mathrm{O} \mathrm{cc}$. of concentrated sulphuric acid contained in a Hempel simple gas pipette. It was then drawn back into the burette and the diminution in volume noted. It was passed back again into the pipette and shaken for another minute and measured. This was repeated several times and the results are given in Table VII. It will be noted that I $8 \mathrm{cc}$. of the 22.5 of ethylene present in the gas mixture was absorbed in thirty minutes, the rate of absorption diminishing as the percentage of ethylene decreased.

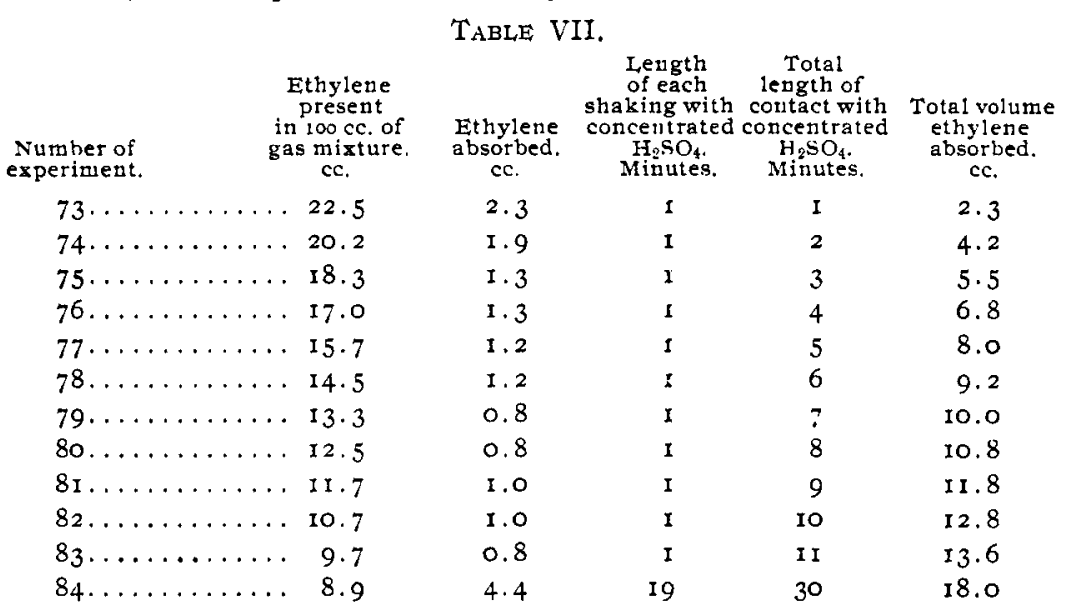

The Action of Concentrated Sulphuric Acid upon a Mixture of Air, Ethylene and Benzene.-A mixture of air, ethylene and benzene containing 1.5 per cent. benzene and Io per cent. ethylene was prepared and was shaken with concentrated sulphuric acid in the manner that Morton describes, except that in Analyses 89 and $9 \mathrm{I}$, the shaking was continued for two minutes instead of only one minute. The results are given in Table VIII. It will be seen that of a total of $11.5 \mathrm{cc}$. of hydrocarbons in $100 \mathrm{cc}$. of the gas mixture, $8.2 \mathrm{cc}$. were absorbed in nine minutes. There was but I.5 per cent. of benzene present in the original mixture and yet 4.3 per cent. of the hydrocarbons was absorbed in the first minute of shaking with the sulphuric acid, demonstrating that at least 2.8 per cent. of ethylene was removed by the reagent. If the analyst is to regard the absorption by sulphuric acid as indicative of the per cent. of benzene present, the actual error in this case would be very 
large. By further shaking of this mixture with the concentrated sulphuric acid from 0.3 per cent. to 0.7 per cent. more of the hydrocarbons was absorbed per minute.

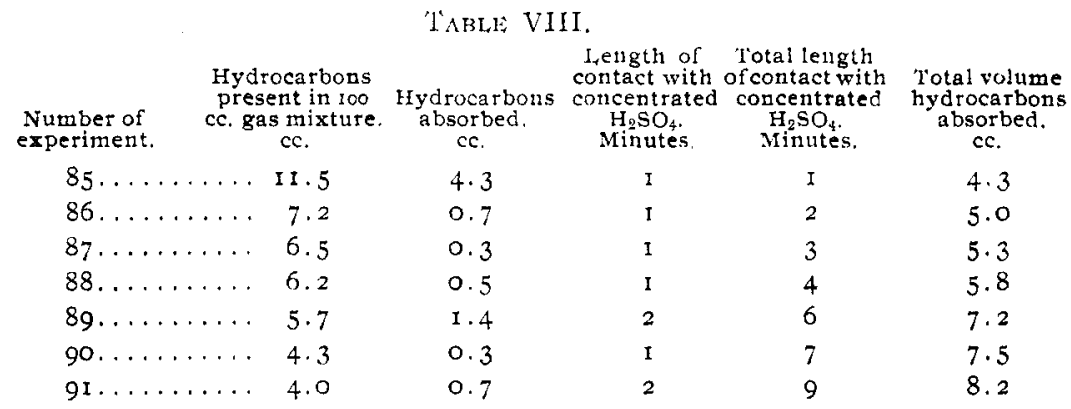

The Action of Concentrated Sulphuric Acid upon Mixtures of Air with Varying Amounts of Ethylene and Benzene.-In this series of experiments the gas mixture was first shaken for one minute with the concentrated sulphuric acid and was then passed into a pipette containing ammoniacal nickel cyanide solution to ascertain whether all of the benzene originally present had been absorbed by the sulphuric acid. An examination of the results in 'Table IX shows that the gas absorbed by the concentrated sulphuric acid is not benzene alone, for upon comparing the figures in the third and fourth columns it will be seen that in Experiments 96 to

TABLE IX.

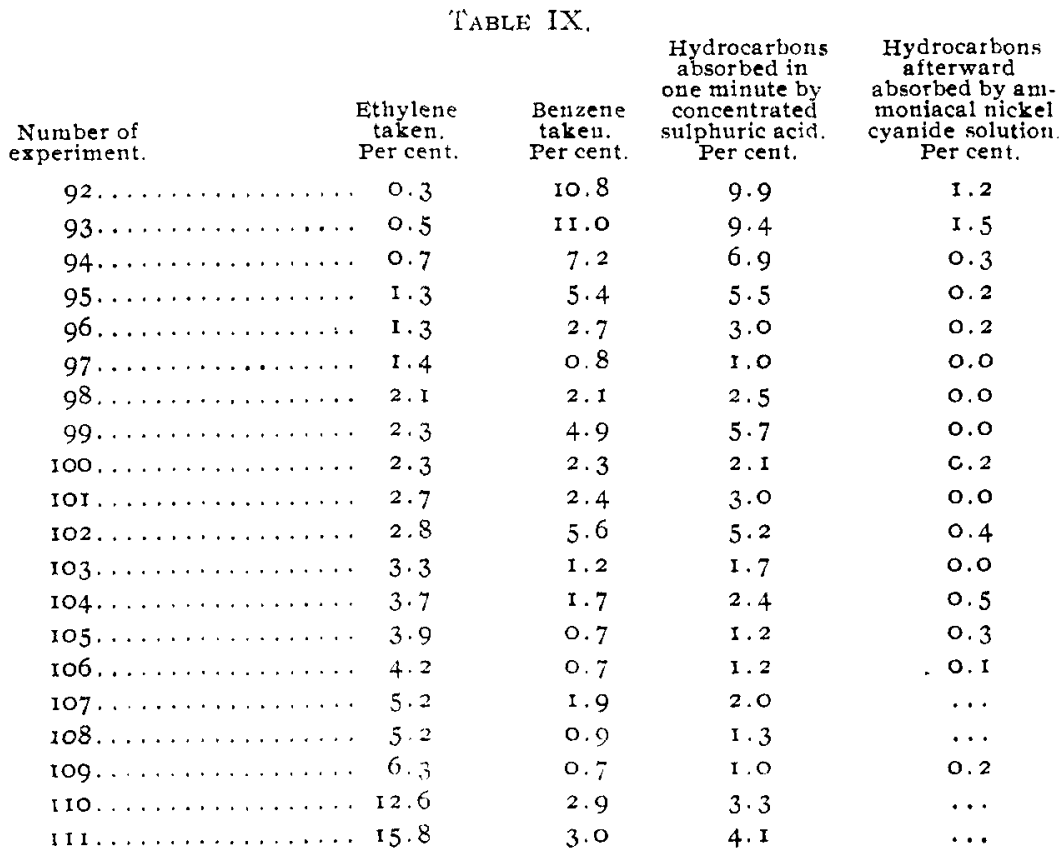


III, with the exception of the rooth and ronnd, the volume of gas absorbed is greater than the volume of benzene taken, in many cases considerably greater. Moreover, the absorption of the benzene by the concentrated sulphuric acid is frequently incomplete, as is demonstrated by the results in the last column. In some cases the measurements showed that the volume of gas absorbed by the sulphuric acid is greater than the volume of benzene added, and yet even in these cases not all of the benzene that had been added was removed by the sulphuric acid. (See in particular, Experiments 96, 104, and 105). The results in Table IX would further demonstrate that with so large and so irregular variations a correction factor for the absorption of ethylene as suggested by Morton would be of no value.

The Determination of Benzene in Coal Gas by means of Concentrated Sulphuric Acid.-A series of determinations (Table X) of benzene in coal gas was made by the Morton method. At the time when these analyses were made the coal gas showed by the ammoniacal nickel cyanide method an average content of less than one per cent. of benzene. The results by the Morton method are in every case much too high and furnish further proof that concentrated sulphuric acid removes other constituents than benzene.

\section{TABLE X.}

\begin{tabular}{|c|c|c|c|}
\hline $\begin{array}{l}\text { Number of } \\
\text { experiment. }\end{array}$ & $\begin{array}{r}\text { Length } \\
\text { with con } \\
\text { sulphu } \\
\text { Min }\end{array}$ & $\begin{array}{l}\text { of contact } \\
\text { ncentrated } \\
\text { uric acid. } \\
\text { nutes. }\end{array}$ & $\begin{array}{l}\text { Hydro- } \\
\text { carbons } \\
\text { absorbed. } \\
\text { Per cent. }\end{array}$ \\
\hline 112 & 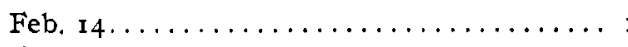 & I & 2.0 \\
\hline 113 & Feb. $14 \ldots \ldots \ldots \ldots \ldots \ldots \ldots \ldots$ & $\mathbf{I}$ & I. 9 \\
\hline 114 & Feb. I $4 \ldots \ldots \ldots \ldots \ldots \ldots \ldots \ldots \ldots \ldots$ & 2 & 2.2 \\
\hline I I 5 & Feb. $14 \ldots \ldots \ldots \ldots \ldots \ldots \ldots \ldots \ldots \ldots$ & 4 & 2.8 \\
\hline I 16 & Feb. I $5 \ldots \ldots \ldots \ldots \ldots \ldots \ldots \ldots \ldots \ldots \ldots$ & $\mathbf{I}$ & I. 7 \\
\hline 117 & 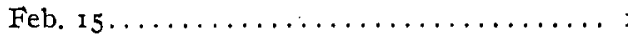 & $\mathbf{I}$ & I. 9 \\
\hline I 8 & Feb. $15 \ldots \ldots \ldots \ldots \ldots \ldots \ldots \ldots \ldots \ldots$ & $\mathbf{I}$ & I. 8 \\
\hline II9 & 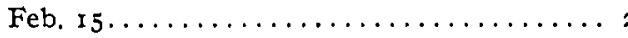 & 2 & 2.1 \\
\hline 120 & Feb. $15 \ldots \ldots \ldots \ldots \ldots \ldots \ldots \ldots \ldots$ & 4 & $2 \cdot 3$ \\
\hline
\end{tabular}

The Effect in the Morton Method of Varying the Speed of Shaking.Morton directs that the gas be passed into the pipette containing the concentrated sulphuric acid and be shaken vigorously (twice per second) with this reagent for one minute. The experiments in Table XI were made to ascertain whether the amount of absorption by the sulphuric acid would vary if the speed at which the pipette is shaken is varied. With acceleration of the shaking slightly higher results were obtained, but they can not be taken as conclusive upon the point at issue, because the concentrated sulphuric acid when shaken foams to so great an extent as to render it difficult to obtain correct measurements of the residual gas volume. Moreover, minute gas bubbles become suspended 
through the sulphuric acid and do not all of them rise to the surface of the reagent even after that has stood undisturbed for two minutes. TABLE XI.

\begin{tabular}{|c|c|c|c|}
\hline $\begin{array}{l}\text { Number of } \\
\text { experiment }\end{array}$ & $\begin{array}{l}\text { I.ength of contact } \\
\text { with reagent. } \\
\text { Minutes. }\end{array}$ & $\begin{array}{l}\text { Number } \\
\text { of shakes } \\
\text { per second. }\end{array}$ & $\begin{array}{l}\text { Hydrocarbons } \\
\text { absorbed. } \\
\text { Per cent. }\end{array}$ \\
\hline I $21 \ldots$ & $\ldots \ldots$ I & 1 & I. 9 \\
\hline $122 \ldots$ & $\ldots \ldots$ & I & 1.8 \\
\hline I $23 \ldots$ & $\ldots \ldots$ & 2 & I. 8 \\
\hline $124 \ldots$ & $\ldots \ldots$ & 2 & 2.0 \\
\hline $125 \ldots$ & $\ldots \ldots$ & 4 & 2.2 \\
\hline $126 \ldots$ & $\ldots \ldots \quad$ I & 4 & 2.3 \\
\hline
\end{tabular}

'To avoid the difficulty that results from the foaming of the reagent, due to shaking, the concentrated sulphuric acid was placed in a pipette of the type used for fuming sulphuric acid. ${ }^{1}$ In the first determination the sample of coal gas was measured in the burette and was then passed into a pipette and drawn back and measured. In the second determination a fresh sample of the gas was taken and was passed into and drawn out from the pipette twice. In the next determination another sample was run into the pipette three times, and so on. The coal gas used in Experiments 127 to 134 inclusive, was found to contain by the ammoniacal nickel cyanide nethod 0.8 per cent. benzene. The sample of gas on the following day, February ioth, Experiments i 35 to I4 I inclusive, contained 0.5 per cent. benzene.

TABLE XII.

\begin{tabular}{|c|c|c|c|}
\hline $\begin{array}{l}\text { Number of } \\
\text { experiment. }\end{array}$ & Date. & $\begin{array}{l}\text { Number of times } \\
\text { gas mixture } \\
\text { passed into } \\
\text { pipette. }\end{array}$ & $\begin{array}{l}\text { Hydrocarbons } \\
\text { absorbed. } \\
\text { Per cent. }\end{array}$ \\
\hline 127 & Feb. I 8. & $\ldots \ldots$ I & I.I \\
\hline 128 & Feb. I 8. & $\ldots$. & I. 2 \\
\hline 129 & Feb. I 8 . & $\ldots$ & I. 4 \\
\hline 130 & Feb. I 8 . & $\ldots \ldots$ & 1.0 \\
\hline 131 & Feb. I 8. & $\ldots$ & 1.6 \\
\hline 132 & Feb. 18. & $\ldots \ldots$ & 1.5 \\
\hline 133 & Feb. 18 & $\ldots \ldots$ & I. 6 \\
\hline 134 & Feb. Is. & $\ldots \ldots$ Io & 2,0 \\
\hline 135 & Feb. I9. & $\ldots \ldots$ & 0.2 \\
\hline 1 36 & Feb. I9. & $\ldots \ldots$ & 0.4 \\
\hline 137 & Feb. Ig. & $\ldots \ldots$ & 0.7 \\
\hline 1.38 & Feb. I9. & $\ldots \ldots$ & T.O \\
\hline 139 & Feb. 19. & $\ldots$ & I. 7 \\
\hline 140 & Feb. I9. & $\ldots .8$ & 2.0 \\
\hline 141 & Feb. I9. & $\ldots$ II & 2,1 \\
\hline
\end{tabular}

The results given in this table show wide variations in the apparent amount of benzene present and demonstrate that the method will not give accurate results even when the foaning is avoided by the use of the fuming sulphuric acid pipette.

'see Hempel's Gas Analysis, page 229. 


\title{
Summary.
}

An ammoniacal solution of nickel cyanide prepared according to the directions given in this article will quantitatively absorb benzene from mixtures containing benzene and air, and from ordinary coal gas. It will not absorb measurable quantities of ethylene or of the other constituents of ordinary coal gas, with the exception of those absorbable in potassium hydroxide solution.

The method proposed by Morton for absorbing benzene by means of sulphuric acid (Sp. Gr. I.84) does not give constant results even when the conditions are the same, and yields widely varying results when the conditions are changed. Moreover, it absorbs both ethylene and benzene, and from mixtures containing both of these gases it does not quantitatively remove the benzene but does remove an indeterminate amount of ethylene. Moreover, in the manipulation suggested by Morton, the reagent foams to such an extent as to make the accurate reading of the gas volumes well nigh impossible.

CORNELL UNIVERSITY,

November, 1907 .

\section{THE EFFECT OF COAL GAS ON THE CORROSION OF WROUGHT IRON PIPE, BURIED IN THE EARTH, ${ }^{1}$}

\author{
BY WM. L. DUDLEY. \\ Received November 14, 1907.
}

This investigation was undertaken in connection with a study of the conditions causing the corrosion of pipe laid under the streets in the City of Nashville.

Five samples of earth were collected as representative of the various types in which the pipes are laid.

Sample No. I was taken from a street at the depth of the gas pipes. It was an old fill. Sample No. 2 was taken from about 4 feet from the surface on private property in the heart of the city, 5o feet from the sidewalk, and was a yellow clay. Sample No. 3 was taken from between the car tracks just under the street metal. It was a loamy clay. Sample No. 4 was a clay taken from a vacant lot in the northern part of the city. Sample No. 5 was taken from under the car tracks in the southern part of the city, and was a mixture of clay and loam.

The analyses of the samples gave the following results in percentages:

$$
\text { Sample. No. I. No. 2. No. 3. No. } 4 . \quad \text { No. } 5 .
$$

$\begin{array}{llllll}\text { Moisture (sample air-dried). . } & 15.37 & 15.82 & 14.4 \mathrm{I} & 13.95 & 14.98\end{array}$

Chlorine............... 0.04204 o.01501 $0.0018 \quad 0.0006 \quad 0.0024$

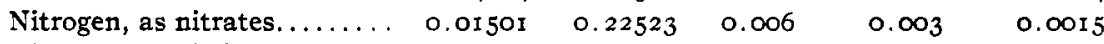

Nitrogen, as nitrites........ $0.00008 \quad 0.000002$ trace none trace

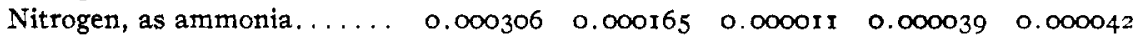

' Read before the New York Section of the American Chemical Society. 